\title{
A PROTEÇÃO CONTRA A DEMISSÃO ARBITRÁRIA NO DIREITO BRASILEIRO: ENTRE A AMBIVALÊNCIA DA CRFB/1988 E OS EFEITOS NEGATIVOS DA DENÚNCIA DA CONVENÇÃO Nº 158 DA OIT
}

\author{
Eleonora Mesquita Ceia* \\ Patrícia Garcia dos Santos**
}

\section{RESUMO}

O trabalho analisa a regulamentação do instituto da proteção contra a demissão arbitrária no direito brasileiro. Pretende examinar o caráter ambíguo, assumido pela CRFB/1988 quando trata do tema da estabilidade no emprego, assim como os efeitos negativos derivados da denúncia por parte do Estado brasileiro da Convenção $\mathrm{N}^{\circ} 158$ da OIT para os direitos fundamentais trabalhistas no Brasil. Demonstra que o quadro normativo vigente não é capaz de assegurar ao trabalhador a proteção contra a demissão arbitrária e defende a restauração da vigência da Convenção no direito brasileiro, ao fortalecer os direitos trabalhistas contra a terminação do contrato de trabalho.

\section{PALAVRAS-CHAVES:}

Direitos fundamentais trabalhistas. Convenção Nº 158 da OIT. Denúncia. Demissão arbitrária. Inconstitucionalidade.

\section{THE PROTECTION AGAINST ARBITRARY DISMISSAL IN BRAZILIAN LAW: BETWEEN THE AMBIVALENCE OF THE CONSTITUTION OF 1988 AND THE NEGATIVE EFFECTS OF THE DENUNCIATION OF THE CONVENTION No 158 OF THE INTERNATIONAL LABOUR ORGANIZATION}

\section{ABSTRACT}

The work analyzes how the institute of protection against unfair dismissals is regulated under Brazilian law. It shows the ambiguous character that the Brazilian Constitution adopts when it deals with the subject of employment stability and the negative effects resulting from the denunciation by Brazil of the Convention $\mathrm{N}^{\circ} 158$ of the ILO on workers' rights in Brazil. It demonstrates that the current legal framework is not capable of protecting workers effective and widely against arbitrary dismissals and, consequently, it defends the restauration of the

\footnotetext{
* Doutora em Direito pela Universidade de Saarbrücken. LL.M. em Direito Europeu pelo Instituto Europa da Universidade de Saarbrücken. Graduada em Direito pela Universidade do Estado do Rio de Janeiro. Ex-bolsista da Fundação Konrad Adenauer. Professora Titular de Direito Constitucional y Direito Internacional Público do Centro Universitário Ibmec-RJ. Endereço postal: Rua da Passagem, 7, apt. 104, Botafogo, 22290-030, Rio de Janeiro - RJ. E-mail: emceia@gmail.com

${ }_{* *}^{*}$ Doutora em Sociologia e Direito pela Universidade Federal Fluminense. Mestre em Sociologia e Direito pela Universidade Federal Fluminense. Graduada em Direito pela Universidade de Fortaleza e Comunicação Social pela Universidade Federal do Ceará. Professora Titular de Direito do Trabalho e Direito Processual do Trabalho do Centro Universitário Ibmec-RJ. Endereço postal: Rua Pereira da Silva, 678, apt. 410, Bloco A, Laranjeiras, 22221-140, Rio de Janeiro - RJ. E-mail: patgarcia85@ hotmail.com

Rev. Revista de Direitos Fundamentais nas Relações do Trabalho, Sociais e Empresariais| e-ISSN: 2525-9903| Evento Virtual| v. 6 | n. 1 | p. 40-61 | Jan/Jun. 2020
} 
Convention's force in Brazilian law, by strengthening labour rights against the termination of employment contract.

KEY WORDS:

Fundamental labour rights. Convention $\mathrm{N}^{\mathrm{o}} 158$ of the International Labour Organization.

Denunciation. Arbitrary dismissal. Unconstitutionality.

\section{Introdução}

O Direito do Trabalho brasileiro, inclusive no período anterior à sistematização da Consolidação das Leis do Trabalho (CLT), em 1943, sempre ressaltou as garantias da continuidade na relação de emprego e a inserção do trabalhador na empresa de forma mais permanente, mediante a criação de mecanismos de afirmação de tais valores.

A partir desta perspectiva tutelar, não obstante ter estabelecido uma nova leitura da garantia da continuidade na relação de emprego, a Constituição da República Federativa do Brasil de 1988 (CRFB/88) assegura, no seu artigo $7^{\circ}$, inciso I, a proteção da relação de emprego contra a demissão arbitrária ou sem justa causa, nos termos da lei complementar, que preverá indenização compensatória, entre outros direitos.

O tema é relevante para oferecer certo equilíbrio mínimo entre os sujeitos da relação (empregado e empregador), que a Declaração Universal dos Direitos Humanos (DUDH), proclamada em 1948, no seio da Organização das Nações Unidas (ONU), dispõe no seu artigo 23 , que toda pessoa tem direito ao trabalho, indicando que o direito ao trabalho inclui, entre outros aspectos, os meios de acesso e a manutenção da relação de emprego.

Nesse contexto, cumpre destacar a Convenção No 158 da Organização Internacional do Trabalho (OIT) que determina aos países signatários a criação de mecanismos institucionais para frear a terminação da relação de trabalho por iniciativa do empregador sem justa causa. O objetivo é garantir que o empregado permaneça no emprego quando, pelo exercício das suas obrigações diárias em conformidade com o disposto no contrato de trabalho, faz jus a esta garantia, notadamente, uma garantia de sobrevivência para aqueles que vivem da sua força laboral.

A Convenção $N^{\circ} 158$ da OIT foi aprovada pelo Congresso Nacional em setembro de 1992, mediante o Decreto Legislativo No 68 e depois, ratificado em janeiro de 1995. Somente em abril de 1996 a Convenção entrou em vigor no direito brasileiro, por meio da publicação

Rev. Revista de Direitos Fundamentais nas Relações do Trabalho, Sociais e Empresariais| e-ISSN: 2525-9903| Evento Virtual| v. 6 | n. 1 | p. 40-61 | Jan/Jun. 2020 


\section{A PROTEÇÃO CONTRA A DEMISSÃO ARBITRÁRIA NO DIREITO BRASILEIRO: ENTRE A AMBIVALÊNCIA DA CRFB/1988 E OS EFEITOS NEGATIVOS DA DENÚNCIA DA CONVENÇÃO N 158 DA OIT}

do Decreto Presidencial $N^{\circ} 1.855$, com o qual o governo brasileiro promulgou o texto oficial do tratado.

Contudo, após sete meses da entrada em vigor do tratado no direito brasileiro, o Presidente da República à época, Fernando Henrique Cardoso, denunciou a ratificação da Convenção $N^{\circ} 158$ mediante o envio de uma nota ao Diretor-Geral da OIT em novembro de 1996. Posteriormente o Presidente promulgou a denúncia mediante o Decreto Presidencial No 2.100 de dezembro de 1996, com o qual anunciava que a Convenção deixaria de estar em vigor a partir de 20 de novembro de 1997.

A ratificação da Convenção $N^{o} 158$ não produziu os efeitos esperados, visto que a maioria das empresas manteve a prática de demitir de acordo com as flutuações do mercado, devido à omissão do Poder Público.

O objetivo deste trabalho é analisar a regulamentação do instituto da proteção contra a demissão arbitrária no direito brasileiro. A partir de uma perspectiva multidisciplinar entre o Direito do Trabalho, Direito Constitucional e o Direito Internacional Público, se pretende examinar, em particular, o caráter ambíguo assumido pela CRFB/88, quando o constituinte trata do tema da estabilidade no emprego, bem como os efeitos negativos derivados da denúncia por parte do Estado brasileiro da Convenção $\mathrm{N}^{\circ} 158$ da OIT para os direitos trabalhistas no Brasil.

O debate do tema proposto é de grande relevância atual para o direito brasileiro, uma vez que, como será explicado adiante, o quadro normativo vigente não é capaz de assegurar geral e efetivamente ao trabalhador a proteção contra a demissão sem justa causa e, por consequência, defende a restauração da vigência da Convenção $\mathrm{N}^{\circ} 158$ no direito brasileiro, com o objetivo de fortalecer os direitos trabalhistas contra o término do contrato de trabalho.

O trabalho está organizado conforme a seguinte estrutura: após esta seção introdutória, na segunda parte, o artigo aborda o instituto legal da estabilidade, examinando criticamente sua evolução histórica no Direito Trabalhista e no Direito Constitucional brasileiro. Em seguida, a terceira parte do artigo não apenas analisa o conteúdo da Convenção No 158 da OIT, como também a sua ratificação e posterior denúncia pelo Estado brasileiro. Ao lado disso, esta parte do trabalho discute a compatibilidade da Convenção e sua denúncia

Rev. Revista de Direitos Fundamentais nas Relações do Trabalho, Sociais e Empresariais| e-ISSN: 2525-9903| Evento Virtual| v. 6 | n. 1 | p. 40-61 | Jan/Jun. 2020 
com a CRFB/88, mediante o estudo das Ações Diretas de Inconstitucionalidade $\mathrm{N}^{\mathrm{o}} 1480$ y N ${ }^{\mathrm{o}}$ 1625, respectivamente. Finalmente, as conclusões apontam os efeitos negativos da denúncia da Convenção $N^{o} 158$ para a proteção do trabalhador no Brasil e resume os argumentos centrais do trabalho.

\section{O instituto da estabilidade no direito trabalhista brasileiro}

A estabilidade compreende o direito do trabalhador de permanecer no emprego, inclusive contra a vontade do empregador, quando não existir causa relevante para justificar a demissão. A perspectiva de que a estabilidade seria uma segurança mínima ao trabalhador contra as condições de desigualdade no mercado de trabalho não é contemporânea com a sistematização do Direito Trabalhista brasileiro. Ela surge pouco depois da Revolução Industrial, quando a limitação do poder do empregador foi fundamental para a concretização dos demais direitos trabalhistas: "Com fundamento em qualquer filosofia sobre a estabilidade, em todas as nações avançadas do mundo a legislação reconhece a legitimidade do princípio da garantia do emprego" (MACEDO; CHAHAD, 1995, p. 23).

Porém, a busca por um crescimento acelerado até o final da Segunda Guerra Mundial, através de políticas que permitiriam alcançar o pleno emprego, teve como resultado não somente o abandono da visão estática da estabilidade, assim como a transmutação do instituto na cena internacional, e posteriormente nos países que foram objeto do mercado globalizado: "Hoje em dia, em muitos países, a lei garante a estabilidade no emprego, após curto prazo, permitindo, todavia, a demissão do trabalhador não apenas devido a atos faltosos cometidos por ele, mas também por razões de ordem estrutural, econômica, financeira ou técnica" (SÜSSEKIND, 2004, p. 130).

O Brasil foi pioneiro quando estabeleceu em 1823, pela Lei Eloy Chaves, o direito à estabilidade no emprego após a expiração de 10 anos aos empregados ferroviários, com a demissão restrita aos casos de falta grave praticada por tais empregados ou de fechamento da instalação ou do setor onde trabalhava. $\mathrm{O}$ direito à estabilidade decenal se estendeu gradualmente a outros grupos profissionais até que se fez chegar a todos os trabalhadores urbanos, com exceção dos trabalhadores domésticos, pela Lei $N^{\circ} 62$ de junho de 1935. Essa Lei foi aprimorada pela CLT e, posteriormente, pela Constituição de 1946 que garantiu a estabilidade aos trabalhadores rurais (artigo 157, XII).

Rev. Revista de Direitos Fundamentais nas Relações do Trabalho, Sociais e Empresariais| e-ISSN: 2525-9903| Evento Virtual| v. 6 | n. 1 | p. 40-61 | Jan/Jun. 2020 
Dessa forma, a estabilidade decenal apareceria no cenário nacional como a melhor tradução do princípio da garantia do emprego. Ainda que estabelecida para frear a vontade livre do empregador na terminação do contrato, o instituto da estabilidade desde sua criação vem sendo objeto de duras críticas baseadas em dois argumentos principais: a) o questionamento da sua efetividade como medida de proteção do trabalhador, tendo em conta a eficiência do setor empresarial para prevenir sua aquisição; e b) os efeitos negativos que o instituto exerceria sobre a produtividade da mão de obra e o funcionamento do mercado de trabalho, porque provocaria indiretamente que o trabalhador se conformasse.

Segundo a visão do empresário brasileiro a estabilidade provocava uma redução intencional na disciplina e na eficiência dos empregados estáveis; dificultava a promoção profissional daqueles que se conformavam na condição de estável; e, principalmente, premiava os piores empregados, devido à dificuldade de comprovar judicialmente as faltas para a autorização da demissão.

Em consonância com o próprio comportamento do mercado, esses argumentos são questionáveis, levando em consideração os mecanismos adequados para corrigir esses comportamentos indesejáveis, como, por exemplo, os casos contemplados como justa causa para a terminação do contrato de trabalho (artigo 482 da CLT), como negligência, indisciplina, insubordinação, ato de má conduta e similares, que servem como base para a terminação judicial.

Esses atos, se comprovados judicialmente como mencionado, liberariam o empregador do dever de indenização ao trabalhador estável por conta do término da relação laboral. Por outra parte, as cifras calculadas pelo Instituto Brasileiro de Geografia e Estatística (IBGE) sobre o resultado dos processos nos tribunais trabalhistas não parecem indicar, ao menos, em princípio, grande dificuldade para o empregador demonstrar a falta grave (FERRANTE, 1978, p. 152).

\subsection{A estabilidade durante a ditadura civil-militar}

Na primeira metade da década de 1960 o governo brasileiro apresentou um anteprojeto preparado pela equipe do Ministério do Trabalho e da Seguridade Social e de 
Planejamento e Coordenação Econômica que, se aprovado eliminaria o direito à estabilidade. Este projeto ofereceria ao trabalhador apenas uma espécie de segurança mediante a indenização por anos de serviço na forma de depósitos mensais, que chega a $8 \%$ da remuneração, em contas vinculadas a seu nome, junto com uma indenização rescisória de $10 \%$ do valor depositado em caso de demissão sem justa causa.

Em virtude das manifestações contrárias ao fim da estabilidade decenal por parte dos sindicatos e das dúvidas acerca da constitucionalidade da medida, o governo retrocedeu com a apresentação do novo anteprojeto, no qual a estabilidade e o sistema do FGTS coexistiriam, ou seja, se concederia ao trabalhador a possibilidade de escolher entre um dos dois regimes.

Em agosto de 1966, o novo anteprojeto se converteu no projeto de lei pelo Presidente da República e entregue ao Congresso Nacional para sua análise. 103 emendas foram apresentadas ao projeto, porém independente delas e por mecanismo autoritário (Ato Institucional $\mathrm{N}^{\mathrm{o}}$ 2) o Presidente converteu o projeto em lei.

Esta medida não só correspondia aos desejos da classe patronal, que postulava contra a estabilidade de 10 anos no emprego, assim como respondia à necessidade da Administração Pública de estabelecer um mecanismo de poupança quase compulsório para garantir ao governo recursos para o financiamento dos setores econômicos e produtivos definidos pela política estatal. Disso resultou três consequências imediatas: a) o aumento da insegurança económica pessoal, com a expansão das taxas de rotação; b) a hesitação dos trabalhadores não estáveis de demandar frente ao Poder Judiciário; e c) a queda dos salários devido às ocupações instáveis (ERICKSON, 1979, p. 217).

Logo, pouco depois do golpe de Estado de $1964^{1}$ foi criado o sistema do FGTS (Lei $\mathrm{N}^{\circ} 5.107 / 66$, atualmente regido pela Lei $\mathrm{N}^{\mathrm{o}}$ 8.036/90) como uma opção ao sistema da estabilidade, permitindo teoricamente que os trabalhadores elegessem expressamente entre o direito ao emprego ou o direito à indenização no momento da celebração do contrato.

Ocorre que, apesar de ter sido assegurado ao trabalhador por lei o direito de escolher entre os regimes, "o que se viu depois da criação do FGTS é a única opção real que o

\footnotetext{
${ }^{1}$ El golpe de Estado de 1964 se refiere al conjunto de acontecimientos que tuvieron lugar entre 31 de marzo y $1^{\circ}$ de abril de 1964 que ha terminado el gobierno democrático del Presidente João Goulart y culminado con el establecimiento de la dictadura cívico-militar en Brasil, que duró hasta 1985, con la elección (aunque indirecta) del primer presidente civil, Tancredo Neves, desde 1964.
}

Rev. Revista de Direitos Fundamentais nas Relações do Trabalho, Sociais e Empresariais| e-ISSN: 2525-9903| Evento Virtual| v. 6 | n. 1 | p. 40-61 | Jan/Jun. 2020 


\section{A PROTEÇÃO CONTRA A DEMISSÃO ARBITRÁRIA NO DIREITO BRASILEIRO: ENTRE A AMBIVALÊNCIA DA CRFB/1988 E OS EFEITOS NEGATIVOS DA DENÚNCIA DA CONVENÇÃO N 158 DA OIT}

empregado pode ter no momento da sua admissão na empresa, [qual seja], era escolher o sistema do FGTS ou permanecer desempregado" (ZANGRANDO, 2008, p. 912).

A partir do momento em que optasse pelo sistema do FGTS, o empregado ficaria automaticamente excluído do sistema da indenização progressiva baseado no tempo de serviço previsto na CLT que subsistia em conjunto com a estabilidade decenal. Como consequência, o empregado não poderia alcançar logicamente a clássica estabilidade no emprego.

Entretanto, o empregado teria o direito de sacar o valor do FGTS, na hipótese de sua demissão sem motivação. A este saque seria acrescido um aumento porcentual rescisório no valor inicialmente de $10 \%$ sobre o montante total do FGTS depositado pelo empregador e corrigido monetariamente (aumento que é de 40\%, desde a promulgação da CRFB/88).

As disposições constitucionais do período autoritário absorveram a inovação e produziram, segundo Maurício Godinho Delgado, um sincretismo jurídico e político curioso sobre esse tema. Isso porque, apesar de que tais disposições fizessem referência ao princípio da continuidade da relação de emprego, que era associado com o antigo sistema da CLT, já incorporavam o contraponto a este princípio, mediante o reconhecimento da validade do sistema do FGTS.

O referido autor cita a Constituição de 1969 que estabelece o direito do trabalhador à integração na vida e no desenvolvimento da empresa (artigo 165, V), ao mesmo tempo invalida a prática do princípio quando admite a noção de ruptura como direito potestativo do empresário por meio do instituto do FGTS (artigo 165, III) (DELGADO, 2014, p. 1310).

Nesse sentido, a discussão legal que ganha força depois de tal medida versa em torno da equivalência entre os dois regimes. Foi construído o entendimento pacífico de que não havia igualdade entre os sistemas, já que os depósitos do FGTS não correspondiam às quantias que seriam pagas aos empregados caso adquirissem a estabilidade decenal e, posteriormente, houvesse a demissão.

Por outro lado, a Constituição utilizava a expressão equivalência, e não igualdade de regimes de direitos. Por conseguinte, os regimes eram diferentes em sua estrutura, mas deveriam ser equivalentes no seu propósito e, deste modo, surgiu a interpretação da palavra

Rev. Revista de Direitos Fundamentais nas Relações do Trabalho, Sociais e Empresariais| e-ISSN: 2525-9903| Evento Virtual| v. 6 | n. 1 | p. 40-61 | Jan/Jun. 2020 
“equivalência" mediante a Súmula 98 do Tribunal Superior do Trabalho brasileiro (TST): “A equivalência entre os regimes do FGTS e da estabilidade da CLT é puramente legal e não econômica, logo, são indevidos quaisquer valores a título de reposição de diferenças".

Assim, ainda que sejam regimes alternativos, cada um com suas vantagens e desvantagens, o direito de livre opção ao trabalhador era dificultado pela pressão exercida pela classe que obteve vantagens evidentes com o FGTS, que concretamente não representou um aumento significativo no custo do trabalhador e permitiu que o empregador incluísse o trabalhador como mais um custo de produção, sujeito às flutuações do mercado. Dessa forma, a estabilidade foi gradualmente minada com o tempo pela nova legislação brasileira, que atualmente considera que a demissão é possível em qualquer caso, sempre e quando haja uma indenização proporcional (DELGADO, 2014, p. 1309).

\subsection{O regime atual da CRFB/1988}

O processo de flexibilização do regime da estabilidade consolida uma situação de inconstitucionalidade, incluindo a falta de respeito pelo direito do trabalhador de eleger e, portanto, necessitava ser revisto por um novo regime constitucional. Se pelas circunstâncias os trabalhadores não podiam exercer livremente seu direito de opção constitucionalmente garantido por um dos regimes, era necessário que a legislação criasse mecanismos que mitigassem uma vez mais a pressão da classe patronal sobre a escolha ou extinguisse um dos regimes. Com isso, a CRFB/88 extingue a estabilidade decenal, através da combinação dos incisos I e III do seu artigo $7^{\circ}$, concluindo a doutrina e a jurisprudência pacificamente que não houve recepção do antigo sistema de proteção.

Como mencionado o modelo clássico da CLT impôs forte intervenção à vontade do empregador em relação à ruptura unilateral, arbitrária e sem motivação do contrato de trabalho. Este modelo previa a conjugação de duas sistemáticas: a indenização progressiva pelo tempo de serviço nas situações de demissão sem justa causa anterior a dez anos e a estabilidade no emprego depois de dez anos de serviço com o mesmo empregador, prazo reduzido pela jurisprudência para efetivos nove anos de serviço (Enunciado No 26 do TST). É certo que este modelo tradicional não impedia, desde o ponto de vista jurídico, o direito unilateral do empregador de romper o contrato de menos de dez anos, mas estabelecia significativo obstáculo de caráter econômico e financeiro para uma medida deste tipo.

Rev. Revista de Direitos Fundamentais nas Relações do Trabalho, Sociais e Empresariais| e-ISSN: 2525-9903| Evento Virtual| v. 6 | n. 1 | p. 40-61 | Jan/Jun. 2020 


\section{A PROTEÇÃO CONTRA A DEMISSÃO ARBITRÁRIA NO DIREITO BRASILEIRO: ENTRE A AMBIVALÊNCIA DA CRFB/1988 E OS EFEITOS NEGATIVOS DA DENÚNCIA DA CONVENÇÃO N 158 DA OIT}

Paradoxalmente, em um momento histórico em que se consagrava o constitucionalismo social no Brasil com ênfase nos valores da dignidade, igualdade e liberdade da pessoa humana, a CRFB/88 acolhe o entendimento de que a garantia do empregado se converte na garantia de indenização (artigo $7^{\circ}$, III). Isso porque a CRFB/88 não menciona a estabilidade de dez anos e estipula a indenização e o FGTS para casos sujeitos à demissão arbitrária ou sem justa causa, mas sem dispor sobre a estabilidade por tempo de serviço.

A CRFB/88 também incluiu, junto à universalização do sistema FGTS e à eliminação do sistema de indenização e da estabilidade de dez anos, a menção inquestionável da restrição ao incumprimento contratual por ato imotivado do empregador. Com essa sistematização, o princípio da garantia do emprego não parece plenamente contemplado e apresenta dúvidas sobre a eficácia imediata do artigo $7^{\circ} \mathrm{I}$ da CRFB/88.

Para José Afonso da Silva e outros constitucionalistas contemporâneos a garantia do emprego significa o direito do trabalhador a reter sua relação laboral, quando não há qualquer razão legal para sua demissão. Assim, a CRFB/88 no reconheceu uma garantia absoluta do emprego, segundo o disposto pela Convenção No 158 da OIT, como se verá a continuação, dado que optou pela fórmula que não é satisfatória, especialmente por estabelecer a necessidade de legislação complementar para definir a proteção à relação de trabalho (AFONSO DA SILVA, 2013, p. 292-293).

Embora pela sua literalidade o artigo $7^{\circ} \mathrm{I}$ da $\mathrm{CRFB} / 88$ possa ser classificado como uma norma constitucional de eficácia limitada, a posição antes citada de José Afonso da Silva de que dito dispositivo é capaz de produzir plenamente seus efeitos encontra apoio em grande parte da doutrina brasileira (AFONSO DA SILVA, 1999, p. 82ss).

Essa posição se baseia no princípio da efetividade, segundo o qual, entre interpretações alternativas e plausíveis, o intérprete constitucional "deverá prestigiar aquela que permite a realização da vontade constitucional, evitando, dentro dos limites possíveis, soluções que se refugiam no argumento da falta de autoaplicabilidade da norma ou da ocorrência da omissão do legislador” (BARROSO, 2009, p. 375-376).

Rev. Revista de Direitos Fundamentais nas Relações do Trabalho, Sociais e Empresariais| e-ISSN: 2525-9903| Evento Virtual| v. 6 | n. 1 | p. 40-61 | Jan/Jun. 2020 
Entre os efeitos mínimos de toda norma constitucional cumpre destacar: a) o efeito negativo (ou a eficácia negativa), que autoriza que sejam declaradas inválidas todas as normas ou atos contrários aos fins previstos pela norma constitucional; e b) o efeito interpretativo (ou a eficácia interpretativa), que estabelece que as normas constitucionais sejam utilizadas como parâmetros de interpretação das outras normas do ordenamento jurídico (BARROSO, 2009, p. 379-380).

Com fundamento nesta argumentação o artigo $7^{\circ} \mathrm{I}$ da CRFB/88, dotado de eficácia mínima negativa, poderia invalidar demissões baseadas no simples exercício potestativo da vontade do empresário, sem um mínimo de justificação socioeconômica, técnica ou pessoal em relação com o trabalhador implicado e, por consequência, solucionando o problema da ambivalência protetora da CRFB/88.

Ainda que predomine a opinião de que a CRFB/88 buscou efetivamente reconhecer o princípio da garantia no emprego e da continuidade da relação trabalhista como princípios de relevância jurídica - rechaçando em seu texto expressamente a demissão arbitrária - se registra que a dinâmica do mercado de trabalho segue ditando o resultado de relação. Isso se explica pelo fato de que o obstáculo da indenização encarece o término sem motivação, porém não impede a totalidade da sua ocorrência, deixando a decisão final à discricionariedade do cálculo que determina se o custo do fim da relação compromete ou não a saúde financeira da empresa.

\section{A Convenção $\mathrm{N}^{\circ} 158$ da OIT e o direito brasileiro}

A Convenção $\mathrm{N}^{\circ} 158$ da OIT sobre o término da relação de trabalho por iniciativa do empregador se originou da Recomendação No 119 sobre a mesma matéria, adotada pela Conferência Geral da OIT em 1963. Esta Recomendação indica que as demissões individuais não deveriam ser arbitrárias, baseadas, por exemplo, em razões sindicais ou discriminatórias (artigo $3^{\circ}$ da Recomendação). Vale dizer, as demissões deveriam apresentar uma causa justificada. Assim, a Recomendação consagrava o direito do trabalhador de permanecer em seu emprego, exceto se o empregador tivesse uma razão válida para terminar a relação de trabalho (artigo 2.1 da Recomendação).

Ao lado disso, o documento reconhecia o direito dos trabalhadores de se defender contra sua demissão, seja através da intervenção de órgãos públicos ou privados, seja por 


\section{A PROTEÇÃO CONTRA A DEMISSÃO ARBITRÁRIA NO DIREITO BRASILEIRO: ENTRE A AMBIVALÊNCIA DA CRFB/1988 E OS EFEITOS NEGATIVOS DA DENÚNCIA DA CONVENÇÃO N 158 DA OIT}

meio de um processo judicial (artigo $4^{\circ}$ da Recomendação) (GALIANA MORENO, 1986, p. 105).

Com base na Recomendação No 119 muitos países reformaram sua legislação com a finalidade de conciliar o direito dos trabalhadores à estabilidade no emprego com outros interesses dos empregadores e da própria economia nacional (SÜSSEKIND, 1987, p. 37).

Por causa das modificações legislativas e da prática dos países, como também das dificuldades econômicas e das mudanças tecnológicas que afetavam cada vez mais o setor laboral, foi aprovada em 1982 pela Conferência Geral da OIT a Convenção No 158, que apresentava significativos avanços em relação à Recomendação $\mathrm{N}^{\circ} 119$. Isso porque, por um lado, o novo documento tinha a forma jurídica de Convenção (MARTINS, 2003, p. 73) ${ }^{2}$ e, por outro, ele detalhava melhor as garantias outorgadas aos trabalhadores em matéria de demissão (GALIANA MORENO, 1986, p. 105).

$\mathrm{O}$ artigo $4^{\circ}$ da Convenção $\mathrm{N}^{\circ} 158$ da OIT estabelece seu princípio básico, segundo o qual a justificação é um requisito prévio essencial para a demissão, deixando proibido, portanto, a demissão injustificada do empregado (ORGANIZAÇÃO INTERNACIONAL DO TRABALHO, 1982). Junto à proibição da demissão arbitrária, a Convenção garante o direito do trabalhador à defesa como um requisito para a realização do término da relação de trabalho, causada pela conduta ou pelo desempenho do empregado, conforme o artigo $7^{\circ}$ da Convenção.

Ademais, conforme o artigo $8^{\circ}$ da Convenção, "o trabalhador que considere injustificado o fim da sua relação de trabalho terá direito a recorrer contra o mesmo perante um organismo neutro, como um tribunal, um tribunal do trabalho, uma junta de arbitragem ou um árbitro" (ORGANIZAÇÃO INTERNACIONAL DO TRABALHO, 1982).

Como destaca Arnaldo Süssekind, o objetivo da Convenção é a reintegração do empregado arbitrariamente demitido, isto é, a anulação do ato de demissão não baseado em alguma das causas no artigo $4^{\circ}$ da Convenção. Sem embargo, a Conferência Geral teve que

\footnotetext{
${ }^{2}$ As recomendações da OIT são instrumentos de soft law carentes de valor jurídico, ou seja, não são vinculantes para os Estados, servindo para estes como meras sugestões de ação, como uma forma de adequar seu direito interno aos padrões internacionais da OIT. As recomendações são, portanto, diferentes das convenções, uma vez que estas são normas juridicamente vinculantes aos Estados ratificantes.
}

Rev. Revista de Direitos Fundamentais nas Relações do Trabalho, Sociais e Empresariais| e-ISSN: 2525-9903| Evento Virtual| v. 6 | n. 1 | p. 40-61 | Jan/Jun. 2020 
flexibilizar esta regra central, a fim de adaptar a Convenção à legislação de muitos países que não reconhecem o direito do trabalhador a regressar ao emprego, quando demitido sem motivação (SÜSSEKIND, 1987, p. 41). Dita norma flexível está prevista no artigo 10 da Convenção.

De acordo com o artigo 10 o órgão deverá anular a demissão e ordenar ou propor a readmissão do empregado, caso tenha competência para fazê-lo, considere a demissão arbitrária e as circunstâncias do caso não desaconselharem a readmissão. Desse modo, recorre-se à indenização ou a qualquer outro tipo de reparação somente quando, apesar de injustificada a demissão, o órgão não seja competente para ordenar a reintegração ou esta seja desaconselhada pelas circunstâncias do caso (SÜSSEKIND, 1987, p. 41).

Em vista do exposto conclui-se que a Convenção tem como princípio fundamental a exigência de justificação para a demissão do trabalhador. Por consequência, a Convenção aponta três possibilidades distintas referentes ao término da relação de trabalho: a) a demissão baseada numa causa justificada relacionada com a capacidade ou o conduta do empregado; b) a demissão baseada numa causa justificada relacionada às necessidades de funcionamento da empresa por razões econômicas, tecnológicas, estruturais ou análogas; e c) a demissão sem motivação ou arbitrária, que acarreta, como regra geral, o direito de reintegração do empregado ou quando tal direito não seja possível, o pagamento de uma indenização ou outra reparação adequada.

\subsection{A ratificação da Convenção $\mathrm{N}^{\mathrm{o}} 158$ pelo Brasil}

Como regra geral a conclusão de tratados internacionais requer o cumprimento de uma série de trâmites, dado que os tratados são atos solenes (CEIA, 2013, p. 11ss). O processo de formação dos tratados internacionais começa com as negociações, que consistem no momento em que as autoridades se reúnem para discutir e acordar sua vontade, com o propósito de que seja adotado um texto comum para o futuro tratado.

Após a adoção do texto do tratado ocorre a assinatura, cuja finalidade é registrar que o tratado foi celebrado com o conhecimento do representante do Estado e que este está de acordo com seus termos. A assinatura é um aceite provisório ao tratado, ou seja, não é legalmente vinculante para o Estado. Ao assinar o Estado somente aceita o conteúdo do tratado negociado, sem expressar sua aceitação definitiva.

Rev. Revista de Direitos Fundamentais nas Relações do Trabalho, Sociais e Empresariais| e-ISSN: 2525-9903| Evento Virtual| v. 6 | n. 1 | p. 40-61 | Jan/Jun. 2020 
No momento posterior à assinatura, na ratificação, o Estado expressa seu consentimento definitivo em obrigar-se por um tratado internacional. Em outras palavras, a ratificação é o ato mediante o qual o Estado confirme a assinatura do tratado e manifesta definitivamente, em nível internacional, sua vontade de cumprir fielmente o tratado.

Depois da ratificação o Estado informa formalmente as outras partes ou uma autoridade especificamente designada que aceitou em obrigar-se definitivamente pelo tratado. Em geral, é partir desta comunicação que o tratado entra em vigor no âmbito internacional para o Estado ratificante, a menos que o tratado em questão disponha de modo diverso. É precisamente o caso da Convenção $\mathrm{N}^{\mathrm{o}} 158$ da OIT, cujo artigo 16 estipula que a Convenção “entrará em vigor doze meses depois da data em que as ratificações de dois Membros tenham sido registradas pelo Diretor-Geral. Desde tal momento, esta Convenção entrará em vigor, para cada Membro, doze meses depois da data em que tiver sido registrada sua ratificação" (ORGANIZAÇÃO INTERNACIONAL DO TRABALHO, 1982).

Ao contrário, a entrada em vigor do tratado internacional no âmbito interno ocorre em conformidade com as normas constitucionais de cada Estado. Em relação ao direito brasileiro, o Supremo Tribunal Federal (STF) estabelece que a incorporação dos tratados internacionais no ordenamento jurídico interno se deriva de um procedimento legislativo complexo (CEIA, 2013, p. 16ss): em primeiro lugar, o tratado internacional deve ser aprovado pelo Congresso Nacional através de um decreto legislativo (artigo 49 I CRFB/1988) e, a continuação, promulgado e publicado pelo Presidente da República mediante um decreto de execução (artigo 84 VIII CRFB/1988).

De acordo com as normas explicadas anteriormente, a Convenção $\mathrm{N}^{\circ} 158$ da OIT foi aprovado pelo Congresso Nacional em 17 de setembro de 1992, mediante o Decreto Legislativo $\mathrm{N}^{\mathrm{o}} 68$ e posteriormente, ratificado em 5 de janeiro de 1995 pelo Presidente Fernando Henrique Cardoso.

Em conformidade com o artigo 16 da Convenção $\mathrm{N}^{\circ}$ 158, doze meses depois dessa data, a saber, no dia 5 de janeiro de 1996, a Convenção entrou em vigor para o Estado brasileiro no âmbito internacional. Contudo, foi apenas no dia 10 de abril de 1996 que a 
referida Convenção entrou em vigor no direito brasileiro, mediante a publicação do Decreto Presidencial $\mathrm{N}^{\mathrm{o}} 1.855$, com o qual o governo brasileiro promulgou o texto oficial do tratado.

Por último, vale registrar a posição hierárquica que a Convenção $\mathrm{N}^{\circ} 158$ assumiu quando incorporada ao direito brasileiro (MAZZUOLI, 2011, p. 366ss). Conforme o atual entendimento do STF, estabelecida na decisão do Recurso Extraordinário (RE) $\mathrm{N}^{\circ}$ 466.343/SP, de 3 de dezembro de 2008, os tratados internacionais podem assumir as seguintes posições no sistema jurídico brasileiro: a) hierarquia de norma constitucional, equivalente às emendas constitucionais, na hipótese de o tratado versar sobre direitos humanos e ser aprovado segundo o rito do artigo $5^{\circ} \S 3^{\circ}$ da $\mathrm{CRFB} / 88$, qual seja, o rito dificultoso de maioria qualificada próprio para a aprovação de emendas constitucionais; b) hierarquia de norma supralegal, quando o tratado internacional verse sobre direitos humanos, mas não tenha sido aprovado segundo o rito do artigo $5^{\circ} \S 3^{\circ}$ da $\mathrm{CRFB} / 88$; e c) hierarquia de lei ordinária, caso o tratado internacional não verse sobre direitos humanos.

Nesta linha de raciocínio, a Convenção $\mathrm{N}^{\circ} 158$ da OIT seria incorporada ao direito brasileiro hoje com status constitucional ou supralegal, dependendo da sua aprovação ou não de acordo com o rito do artigo $5^{\circ} \S 3^{\circ}$ da CRFB/88. Isso se deve ao fato de que a Convenção $\mathrm{N}^{\mathrm{o}} 158$ é um tratado internacional sobre direitos humanos, visto que as convenções internacionais em matéria trabalhista integram, desde muito tempo, o Direito Internacional dos Direitos Humanos (BORGES, 2009, p. 591).

No entanto, quando a Convenção $\mathrm{N}^{\mathrm{o}} 158$ foi incorporada ao direito brasileiro, em 1996, o STF adotava a teoria da paridade normativa entre os tratados internacionais e as leis ordinárias. Quer dizer, aos tratados internacionais foi conferido o mesmo status hierárquico que as leis ordinárias, independentemente da matéria versada pelo tratado. Logo, a Convenção $\mathrm{N}^{\mathrm{o}} 158$ assumiu a posição de lei ordinária quando foi incorporada ao direito brasileiro.

3.2. A Ação Direta de Inconstitucionalidade No 1480: o conflito entre a Convenção e o artigo $7^{\circ} \mathrm{I}$ da CRFB/1988

Pouco depois da sua incorporação ao direito brasileiro, em setembro de 1997, a constitucionalidade da Convenção $\mathrm{N}^{\mathrm{o}} 158$ foi questionada perante o STF pela Confederação Nacional da Indústria. Esta entidade considerava que a Convenção era incompatível com a CRFB/88, tanto formalmente quanto materialmente. Para ela, a Convenção seria 


\section{A PROTEÇÃO CONTRA A DEMISSÃO ARBITRÁRIA NO DIREITO BRASILEIRO: ENTRE A AMBIVALÊNCIA DA CRFB/1988 E OS EFEITOS NEGATIVOS DA DENÚNCIA DA CONVENÇÃO No 158 DA OIT}

materialmente incompatível com a CRFB/88, já que os artigos $4^{\circ}$ e 10 da Convenção contrariavam a regra do artigo $7^{\circ} \mathrm{I}$ da CRFB/88. Enquanto os dispositivos da Convenção garantem a possibilidade da restauração da relação de emprego, a regra da CRFB/88 oferece somente o pagamento da indenização na hipótese da demissão sem justa causa. De outra parte, a Convenção seria formalmente incompatível com a CRFB/88, pois trata de matéria reservada à lei complementar.

O relator do caso, o Ministro Celso de Mello, aceitou parcialmente a petição da Confederação. Por um lado, sustentou que a Convenção é formalmente incompatível com a $\mathrm{CRFB} / 88$, pois os tratados internacionais não podem, com efeito, tratar de matérias reservadas pela CRFB/88 à legislação complementar. Por outro lado, votou a favor da constitucionalidade material da Convenção com fundamento numa interpretação conforme a Constituição, a saber: o artigo 10 da Convenção estabelece que o Estado pode optar pelo pagamento de uma indenização no lugar da reintegração no emprego no caso de despedida arbitrária. Uma vez que a Convenção tem conteúdo programático, ou seja, sua aplicabilidade depende do tratamento por lei posterior, seria possível, segundo o Relator, adequar as diretrizes da Convenção aos requisitos da CRFB/88, em particular, substituir a reintegração ao emprego pelo pagamento de indenização ao trabalhador (BORGES, 2009, p. 586).

Cumpre assinalar a posição contrária do Ministro Carlos Velloso, quem entende que a Convenção é plenamente constitucional. Para o Ministro, a Convenção é uma norma de eficácia plena e aplicabilidade imediata, que introduziu ao direito brasileiro um direito fundamental não previsto originalmente na $\mathrm{CRFB} / 88$, qual seja, o direito do trabalhador de sua reincorporação ao emprego no caso de despedida sem motivação. O Ministro respaldou sua posição no entendimento de que a Convenção, por ser um tratado internacional sobre direitos humanos, tem hierarquia de norma constitucional, com fundamento no artigo $5^{\circ} \S 2^{\circ}$ da CRFB/88 (BORGES, 2009, p. 586-587). Não obstante, em junho de 2001, o processo foi extinto sem a resolução do mérito, devido à perda posterior do objeto da ação decorrente da denúncia da Convenção No 158 da OIT pelo Brasil.

\subsection{A denúncia da Convenção pelo Brasil}

Rev. Revista de Direitos Fundamentais nas Relações do Trabalho, Sociais e Empresariais| e-ISSN: 2525-9903| Evento Virtual| v. 6 | n. 1 | p. 40-61 | Jan/Jun. 2020 
A denúncia é o ato unilateral pelo qual uma das partes de determinado tratado internacional expressa sua decisão firme de deixar de ser parte do acordo anteriormente firmado. Em geral, os tratados internacionais permitem a retirada unilateral em qualquer momento. Portanto, em teoria, uma das partes pode retirar-se pouco depois da entrada em vigor do tratado. Apenas se requer a expiração de um prazo de acomodação, segundo o interesse dos copactuantes. Na prática, o Estado que deseja retirar-se do tratado deve notificar sua decisão às demais partes, mas somente desvincular-se do tratado depois do curso do prazo previsto. O artigo $56 \S 2^{\circ}$ da Convenção de Viena sobre o Direito dos Tratados de 1969 (CVDT) estabelece como regra geral o prazo de doze meses (MAZZUOLI, 2011, p. 304-306). No direito brasileiro há uma controvérsia importante com respeito ao órgão competente para denunciar tratados internacionais, a saber: pode o Presidente da República, por ato próprio, denunciar tratados internacionais, cuja ratificação requer a aprovação do Congresso Nacional? Sobre isso a CRFB/88 silencia e a doutrina é divergente. Uma parte se pronuncia a favor da denúncia sem a participação do Congresso Nacional, pois considera que a intervenção legislativa somente é necessária para a ratificação dos tratados, de acordo com o artigo 84 VIII da CRFB/88. Para a denúncia não há obrigação semelhante prevista no texto constitucional.

Enquanto outra parte da doutrina sustenta que a participação do Congresso Nacional para denunciar os tratados é necessária com fundamento na competência exclusiva do Congresso para resolver definitivamente sobre tratados, em conformidade com o artigo 49 I da CRFB/88. Baseada nesta competência defende que o Presidente da República tem a obrigação de submeter ao Congresso Nacional toda denúncia de tratado internacional pelo Estado brasileiro. Esta posição considera a existência do princípio do "ato contrário" ou da simetria, que enuncia: se a ratificação do tratado depende da aprovação prévia do Congresso Nacional, da mesma maneira, para a denúncia, ou seja, para o ato contrário à ratificação, o Presidente da República necessita da autorização do Congresso.

Em relação à Convenção $N^{o} 158$, o Presidente da República à época, Fernando Henrique Cardoso, denunciou o tratado, sem o consentimento do Congresso Nacional, através de uma nota enviada à OIT em 20 de novembro de 1996. Pelo Decreto $\mathrm{N}^{\mathrm{o}} 2.100$, de 20 de dezembro de 1996, o Presidente faz pública a denúncia e, por consequência, determina que a Convenção deixará de vigorar no Brasil a partir de 20 de novembro de 1997. Vale ressaltar

Rev. Revista de Direitos Fundamentais nas Relações do Trabalho, Sociais e Empresariais| e-ISSN: 2525-9903| Evento Virtual| v. 6 | n. 1 | p. 40-61 | Jan/Jun. 2020 


\section{A PROTEÇÃO CONTRA A DEMISSÃO ARBITRÁRIA NO DIREITO BRASILEIRO: ENTRE A AMBIVALÊNCIA DA CRFB/1988 E OS EFEITOS NEGATIVOS DA DENÚNCIA DA CONVENÇÃO N 158 DA OIT}

que o período de vigência da Convenção no Brasil durou apenas 19 meses (entre a promulgação do Decreto $N^{o} 1.855$ em abril de 1996 e novembro de 1997, quando a Convenção perde sua validade).

O governo motivou sua decisão de denunciar a Convenção no fato de que a manutenção de sua vigência prejudicaria o País em termos de competitividade internacional. Outrossim, os questionamentos sobre a constitucionalidade da Convenção geraram numerosos litígios perante os tribunais nacionais.

Em fevereiro de 2008, o Presidente Luiz Inácio Lula da Silva enviou ao Congresso Nacional novo pedido de exame da Convenção $\mathrm{N}^{\circ} 158$ da OIT, para efeitos de sua posterior ratificação. O processo de análise da Convenção está, todavia, em trâmite no Congresso Nacional.

3.4. A Ação Direta de Inconstitucionalidade Nº 1.625: a controvérsia sobre a denúncia de tratados internacionais no direito brasileiro

Frente à controvérsia acerca da necessidade de autorização do Congresso Nacional para a denúncia de um tratado internacional pelo Presidente da República, em fevereiro de 1997, a Confederação Nacional dos Trabalhadores da Agricultura propõe a Ação Direta de Inconstitucionalidade $N^{o} 1.625$ perante o STF. Através desta ação a Confederação questionava a constitucionalidade do Decreto $\mathrm{N}^{\circ} 2.100$ do Presidente da República, que fez pública a denúncia da Convenção $\mathrm{N}^{\circ} 158$ pelo Estado brasileiro, sobre a base da necessidade de consentimento do Congresso Nacional para a denúncia de dito tratado.

O caso está ainda pendente de julgamento pelo STF. Porém, importa destacar o conteúdo dos votos emitidos até o momento. O relator do caso, o ex-Ministro Maurício Corrêa, e o ex-Ministro Carlos Britto votaram, parcialmente, a favor da Confederação, com fundamento em uma interpretação conforme do Decreto ao artigo 49 I da CRFB, determinando que a denúncia da Convenção requer o consentimento do Congresso Nacional.

Neste mesmo sentido o ex-Ministro Joaquim Barbosa respaldou o pedido da Confederação, mas, no lugar de adotar a solução da interpretação conforme, defendeu a declaração de inconstitucionalidade integralmente do Decreto. Segundo ele, nenhuma das

Rev. Revista de Direitos Fundamentais nas Relações do Trabalho, Sociais e Empresariais| e-ISSN: 2525-9903| Evento Virtual| v. 6 | n. 1 | p. 40-61 | Jan/Jun. 2020 
Constituições brasileiras versou sobre o tema específico da denúncia dos tratados internacionais. Ainda que os artigos 49 I e 84 VIII da CRFB/88 não reconhecem a participação do Congresso Nacional na denúncia dos tratados, tampouco proíbem expressamente dita participação.

Entre outros argumentos, o Ministro alega que a CRFB/88 integra a tendência atual no direito comparado de adotar o princípio da coparticipação entre o parlamento e o governo no campo dos tratados internacionais. Conforme este princípio a própria natureza do tratado requer - para que o mesmo vincule um Estado externa e internamente - a resolução do Poder Legislativo e do Poder Executivo e, em consequência, qualquer ato dirigido à retirada voluntária do tratado por um Estado também necessita submeter-se ao exame parlamentário (SUPREMO TRIBUNAL FEDERAL, 2009, p. 23).

Sobre os efeitos de uma possível declaração de inconstitucionalidade do Decreto $\mathrm{N}^{\mathbf{o}}$ 2.100 o Ministro esclarece:

\begin{abstract}
Em virtude de a denúncia já estar produzindo efeitos no âmbito internacional creio que seja importante esclarecer duas consequências derivadas da declaração de inconstitucionalidade. Em primeiro lugar: a declaração de inconstitucionalidade somente terá o fato de fazer o ato de denúncia não obrigatório no Brasil, por falta de publicidade. Em consequência, o Decreto que internalizou a Convenção 158 da OIT no Brasil se mantém em vigor. Se o Presidente da República deseja que a denúncia produza efeitos também internamente, deverá pedir autorização do Congresso Nacional e, apenas então, promulgar novo decreto dando publicidade da denúncia já realizada em nível internacional. Em segundo lugar: a declaração de inconstitucionalidade só afeta o decreto que deu a conhecer a denúncia. Nada impede que o Presidente da República ratifique a Convenção 158 da OIT de novo. A possibilidade de rerratificação de tratados é concreta, inclusive, já ocorreu no Brasil com a Convenção 81, da OIT, cuja denúncia se fez pública pelo Decreto 68.796/71, mas foi de novo ratificada e incorporada a nosso sistema mediante o Decreto $\mathrm{N}^{\circ}$ 95.461/1987, que revitalizou o Decreto 41.721/1957, que originalmente incorporou ao direito nacional tal Convenção (SUPREMO TRIBUNAL FEDERAL, 2009, p. 42-43).
\end{abstract}

Em novembro de 2015, a Ministra Rosa Weber anunciou seu voto e, de igual maneira, votou a favor do pedido da Confederação. Seu voto partiu da premissa de que o decreto, que fez pública a denúncia da Convenção, és formalmente inconstitucional. Isso se deve ao fato de que, segundo a Constituição, leis ordinárias não podem ser revogadas pelo Presidente da República, e o decreto que formaliza a adesão do Brasil a um internacional, aprovado e ratificado pelo Congresso, é equivalente à lei ordinária (SUPREMO TRIBUNAL FEDERAL, 2009). 


\section{A PROTEÇÃO CONTRA A DEMISSÃO ARBITRÁRIA NO DIREITO BRASILEIRO: ENTRE A AMBIVALÊNCIA DA CRFB/1988 E OS EFEITOS NEGATIVOS DA DENÚNCIA DA CONVENÇÃO N 158 DA OIT}

Ao revés, o ex-Ministro Nelson Jobim se apartou dos votos anteriores, para decidir pela improcedência do pedido. O Ministro considerou que o Presidente da República, pelo fato de representar a União em nível internacional, pode unilateralmente, sem a autorização do Congresso Nacional, denunciar tratados internacionais. Para o Ministro, o Decreto Legislativo, mediante o qual o Congresso Nacional aprova o tratado, inclui a aceitação tácita da possibilidade de que o Presidente da República denuncie o tratado.

Na doutrina se encontra posição favorável ao voto do Relator. Com efeito, não seria razoável supor que o Presidente da República pudesse, unilateralmente, por meio de um decreto, suprimir direitos - às vezes, considerados fundamentais para a pessoa humana, como os direitos trabalhistas - previstos em tratados internacionais incorporados ao direito brasileiro. Seria um ato contrário ao Estado de Direito, visto que eliminaria a resolução parlamentária da matéria (BORGES, 2009, p. 590).

\section{Conclusões}

A denúncia da Convenção $\mathrm{N}^{\circ} 158$ teve um impacto negativo no ordenamento jurídico brasileiro no que se refere à proteção dos direitos do trabalhador. Isso porque a Convenção introduziria ao direito interno a exigência de motivação para todas as espécies de término da relação de trabalho. Em outras palavras, ela seria capaz de assegurar que não houvesse mais a demissão de um trabalhador a menos que existisse para ela uma causa justificada relacionada com a capacidade ou conduta do empregado ou com as necessidades de funcionamento da empresa por razões econômicas, estruturais ou análogas.

Vale destacar que a Convenção não proibiria a despedida do trabalhador no Brasil e, portanto, não restringiria excessivamente a liberdade do empregador - mas apenas a despedida arbitrária. Quer dizer, a incorporação da Convenção ao direito brasileiro exigiria que a demissão do empregada fosse motivada.

Desde esta perspectiva, a Convenção traria uma moderação necessária para o sistema brasileiro em vigor, que garante ao empregador ampla liberdade no término da relação de trabalho. Isso tendo em vista que mediante a proibição da demissão arbitrária seria garantido 
um justo equilíbrio entre o direito do empregado à estabilidade e o direito do empregador à liberdade de iniciativa.

Efetivamente, a Convenção $\mathrm{N}^{\mathrm{o}} 158$ proporciona uma proteção mais ampla ao trabalhador em relação à demissão arbitrária que o sistema atual do Brasil, que não impõe ao empregador qualquer obrigação de justificar o motivo da despedida sem justa causa. Por conseguinte, a denúncia da Convenção representa um claro retrocesso para o Direito Constitucional e Trabalhista brasileiro. De outra parte, a denúncia restaura a ambivalência da CRFB/88 no tratamento do instituto da estabilidade, contrária ao caráter original neoconstitucionalista da Constituição brasileira baseada no princípio da dignidade humana e na defesa dos direitos humanos.

Precisamente sobre a base do compromisso da CRFB/88 com os direitos humanos e fundamentais que se defende a compatibilidade da Convenção com o texto constitucional brasileiro, como propugnado pelo Ministro Carlos Velloso na ADI No 1.450. Deste modo, a Convenção deve ser considerada uma norma internacional sobre direitos humanos, de hierarquia constitucional, de plena eficácia e aplicabilidade imediata. Consequentemente, a Convenção não poderia ter sido denunciada, unilateralmente, pelo Presidente da República, pois dita denúncia retirou, de forma arbitrária, um direito fundamental do trabalhador incorporado plenamente à ordem constitucional brasileira, o que viola não apenas o princípio da proibição do retrocesso, como também o próprio conceito de Estado de Direito.

Todos esses argumentos concluem a favor da restauração da vigência da Convenção $\mathrm{N}^{\mathrm{o}} 158$ da OIT no direito brasileiro. Para tanto existem duas possibilidades em curso: o Congresso Nacional aceitar o pedido enviado pelo governo em 2008 para aprovar a Convenção; e o STF declarar a inconstitucionalidade do Decreto No 2.100 de 1996 e, por consequência, exigir que o Congresso Nacional decida sobre a conveniência da denúncia da Convenção $N^{\circ} 158$ pelo Estado brasileiro. Em qualquer hipótese, espera-se que os agentes públicos decidam de acordo com a natureza redemocratizante da CRFB/88 e, portanto, recepcionem nova e definitivamente a Convenção $\mathrm{N}^{\mathrm{o}} 158$ da OIT ao direito brasileiro.

\section{Referências}

Rev. Revista de Direitos Fundamentais nas Relações do Trabalho, Sociais e Empresariais| e-ISSN: 2525-9903| Evento Virtual| v. 6 | n. 1 | p. 40-61 | Jan/Jun. 2020 


\section{A PROTEÇÃO CONTRA A DEMISSÃO ARBITRÁRIA NO DIREITO BRASILEIRO: ENTRE A AMBIVALÊNCIA DA CRFB/1988 E OS EFEITOS NEGATIVOS DA DENÚNCIA DA CONVENÇÃO N 158 DA OIT}

AFONSO DA SILVA, José. Aplicabilidade das normas constitucionais. 3. ed. São Paulo: Malheiros, 1999.

AFOnSO DA SILVA, José. Curso de Direito Constitucional Positivo. São Paulo: Malheiros, 2013.

BARROSO, Luís Roberto. Interpretação e Aplicação da Constituição. 7. ed. São Paulo: Saraiva, 2009.

BARROSO, Luís Roberto. Curso de Direito Constitucional Contemporâneo: os conceitos fundamentais e a construção do novo modelo. 3. ed. São Paulo: Saraiva, 2011.

BORGES, Daniel Damásio. “O Direito ao Trabalho - Reflexões em torno da superação de uma clássica distinção entre direitos civis e políticos e direitos econômicos, sociais e culturais". In: AMARAL JUNIOR, Alberto do; JUBILUT, Liliana Lyra (Orgs.). O STF e o Direito Internacional dos Direitos Humanos. São Paulo: Quartier Latin, 579-599, 2009.

CEIA, Eleonora Mesquita. La conclusión de tratados internacionales en el derecho comparado: un estudio comparativo entre América Latina y Europa. Saarbrücken: Akademikerverlag, 2013.

DELGADO, Maurício Godinho. Curso de Direito do Trabalho. São Paulo: Ltr, 2014.

ERICKSON, Kenneth Paul. Sindicalismo no Processo Político no Brasil. São Paulo: Brasiliense, 1979.

FERRANTE, Vera Lúcia Botta. FGTS: ideologia e repressão. São Paulo: Ática, 1978.

GALIANA MORENO, Jesus Maria. "El Convenio No 158 de la OIT y su incidencia en los despidos individuales”, Revista Jurídica de la Región de Murcia, n. 4), 103-112, 1986.

MACEDO, Roberto; CHAHAD, José Paulo Zeetano. FGTS e a Rotatividade. São Paulo: Nobel, 1995.

MARTINS, Sérgio Pinto. Direito do Trabalho. 22. ed. São Paulo: Atlas, 2006.

ORGANIZAÇÃO INTERNACIONAL DO TRABALHO. Convenção No 158 sobre a terminação de relação de trabalho por iniciativa do empregador. 1982. Disponível em: <http://www.ilo.org/dyn/normlex/es/f?p=NORMLEXPUB:12100:0::NO:12100:P12100_ILO _CODE:C158>. Acesso em: 12 abr. 2020.

Rev. Revista de Direitos Fundamentais nas Relações do Trabalho, Sociais e Empresariais| e-ISSN: 2525-9903| Evento Virtual| v. 6 | n. 1 | p. 40-61 | Jan/Jun. 2020 
MAZZUOLI, Valerio de Oliveira. Curso de Direito Internacional Público. 5. ed. São Paulo: Editora Revista dos Tribunais, 2011.

SUPREMO TRIBUNAL FEDERAL. Íntegra do Voto-vista do Ministro Joaquim Barbosa na ADI $\quad \mathbf{N}^{\circ} \quad \mathbf{1 . 6 2 5}$ 2009. Disponível em: <http://www.stf.jus.br/portal/cms/verNoticiaDetalhe.asp?idConteudo=110042>. Acesso em: 12 abr. 2020.

SUPREMO TRIBUNAL FEDERAL. "Em voto-vista, ministra considera inconstitucional decreto que revogou convenção da OIT”. 2015. Disponível em: <http://www.stf.jus.br/portal/cms/verNoticiaDetalhe.asp?idConteudo=303837>. Acesso em: 12 abr. 2020.

SÜSSEKIND, Arnaldo. Garantia contra a despedida arbitrária. 1987. p. 31-44. Disponível em:

<http://www.tst.jus.br/documents/1295387/1334672/2.+Garantia+contra+a+despedida+arbitr \%C3\%A1ria>. Acesso em: 12 abr. 2020.

SÜSSEKIND, Arnaldo. Instituições do Direito do Trabalho. São Paulo: Ltr, 2004.

ZANGRANDO, Carlos Henrique (2008): Curso de Direito do Trabalho (São Paulo, Ltr). 